\title{
A MOTIVAÇÃO NO ENSINO SUPERIOR: UM ESTUDO COM ALUNOS DOS CURSOS DE ADMINISTRAÇÃO E DIREITO
}

\section{RESUMO}

Thalita Lima Ferreira da

Silva

Graduanda em Administração

- Unichristus- Fortaleza-CE-

BR <thalitalimaf@gmail.

com $>$

Iago Pessoa

Mascarenhas

Graduando em

Administração - Unichristus

- Fortaleza-CE-BR <iago.

pessoa@yahoo.com.br>

Caio Pinheiro de

Medeiros

Graduando em

Administração - Unichristus

- Fortaleza-CE-BR < caio_

pm1@hotmail.com>

Ellen Campos Sousa

Mestre em Administração -

Unichristus - Fortaleza-CE-

BR <contato.ellencampos@

gmail.com $>$
A motivação do aluno é um dos componentes essenciais para a aprendizagem. De acordo com a teoria de autodeterminação, essa motivação pode ser intrínseca e extrínseca e a ausência dela gera a desmotivação. O objetivo deste trabalho é: identificar a motivação para aprendizagem dos discentes de Administração e Direito de um Centro Universitário em Fortaleza-Ce e as possíveis diferenças em razão dos cursos, turnos e semestres dos alunos. Para se chegar ao resultado, realizou-se uma pesquisa quantitativa, tendo como instrumento de pesquisa um questionário adaptado e validado para o Ensino Superior por Sobral (2003). A escala utilizada trabalha os constructos de motivação intrínseca, extrínseca e desmotivação. A amostra resultou em 105 questionários válidos. A análise dos dados mostrou que os alunos dos dois cursos estão motivados por fatores intrínsecos e extrínsecos, havendo diferença entre os turnos no curso de Administração.

Palavras-chave: Motivação. Ensino Superior. Administração. Direito.

\section{INTRODUÇÃO}

Um curso de ensino superior é cada vez mais procurado, visto que cada vez mais o mercado de trabalho exige qualificação profissional. Atualmente, essa demanda vem, em grande parte, sendo atendida pelas instituições privadas, mas nem sempre foi assim. Foi a partir das mudanças que ocorreram na educação superior do Brasil na década de 1990 (com a promulgação da Lei de Diretrizes e Base da Educação, em 1996) que se mudou a relação entre o Estado e a educação, promovendo uma desburocratização para ofertas 
de vagas no ensino superior (MATHIAS, 2004). Com o incentivo à expansão do setor para organizações privadas, desde então houve um crescimento enfatizado na quantidade de cursos superiores em todo o país.

$O$ ingresso em uma formação superior no Brasil tem suas dificuldades que partem desde a escolha do curso à sua conclusão. Entretanto, após ingressarem no curso, muitos alunos acabam evadindo. De acordo com Silva Filho et al. (2007), as perdas relacionadas à evasão são grandes no setor privado, pois além da perda de receitas, a evasão ocasiona a ociosidade dos recursos humanos e ainda de equipamentos e do espaço físico. Entende-se que um dos principais fatores que podem levar à evasão é a desmotivação do aluno para com o curso ou a instituição.

A motivação pessoal é reconhecidamente um fator de destaque no estudo do comportamento, podendo ela advir de estímulos externos ou internos. Desta forma, acredita-se que a motivação do aluno é um dos componentes essenciais para a aprendizagem (GUIMARÃES; BORUCHOVIT$\mathrm{CH}, 2004)$ e, consequentemente, um fator diretamente relacionado à permanência do aluno no curso.

Diversos estudos foram realizados para identificar a motivação dos alunos diante do serviço prestado em forma de ensino (JOLY; PRATES, 2011; SOBRAL, 2003). Entretanto, este não é um assunto finalizado, visto que cada instituição e cada aluno possuem suas peculiaridades. Desta forma, percebe-se a importância da contínua realização de pesquisas para acompanhar a motivação geral do aluno, a fim de concluir os estudos e não evadir. Entende-se que este estudo tem grande relevância para a instituição, sendo este um valioso instrumento para a gestão da universidade.
A partir deste entendimento, este estudo traz o seguinte objetivo geral: identificar a motivação para aprendizagem dos discentes de Administração e Direito de um Centro Universitário em Fortaleza-Ce e as possíveis diferenças em razão dos cursos, turnos e semestres dos alunos.

Desta forma, apresentam-se os seguintes objetivos específicos: identificar os percentuais de motivações intrínseca e extrínseca e de desmotivação dos alunos dos cursos de Administração e Direito; comparar as médias de motivações intrínseca e extrínseca e de desmotivação dos alunos dos cursos de Administração e Direito em relação ao turno que cursam; comparar as médias de motivações intrínseca e extrínseca e de desmotivação dos alunos dos cursos de Administração e Direito em relação ao semestre que cursam; apresentar o grau de motivação global para prosseguir nos estudos e se formar dos alunos dos cursos de Administração e Direito.

Para atender aos objetivos propostos, foi realizada uma pesquisa quantitativa com estudantes dos cursos de Administração e Direito de um Centro Universitário em Fortaleza/CE. A escala utilizada foi adaptada e validada para o segmento do ensino superior por Sobral (2003). Os dados foram trabalhados com auxílio do software SPSS (Statistical Package for the Social Sciences) versão 19.0, módulos de estatística descritiva, Análise de Médias e Análise de Variância (ANOVA).

\section{MOTIVAÇÃO NO ENSINO SUPERIOR}

Compreender a motivação humana tem sido um desafio. De acordo com Almeida (2012), várias investigações têm sido rea- 
lizadas e diversas teorias têm tentado explicar o funcionamento desta força que leva as pessoas a agirem em prol do alcance de objetivos. A motivação é um dos determinantes principais de rendimento individual. Outras variáveis, como o esforço, as capacidades individuais, o suporte social e a experiência prévia também influenciam o rendimento, podendo haver também variáveis de caracterização pessoal, percepção do aluno acerca do curso, o objetivo de concluir os estudos e atuar na área de formação, o desempenho alegado e a visualização do esforço do aluno (ALMEIDA, 2012).

A palavra motivação provém do latim movere, cujo supino motum e o substantivo motivum, do latim tardio, deram origem ao termo, semanticamente aproximado, motivo. Assim, a palavra motivação é derivada do verbo motivar e refere-se ao motivo, àquilo que move a pessoa, que a faz entrar em ação e a impulsiona para algum objetivo. Também é entendida na língua portuguesa como o conjunto de fatores psicológicos, de ordem fisiológica, intelectual ou afetiva, os quais, agindo em conjunto, determinam a atividade e a conduta do indivíduo (FERREIRA, 2006 apud ALMEIDA, 2012).

Em especial, no meio educacional, a motivação tem sido apontada como fator psicopedagógico que afeta diretamente o comportamento dos estudantes no meio escolar. Pesquisas têm avançado com a finalidade de investigar o impacto deste fenômeno na aprendizagem e no desenvolvimento educativo (GAGNÉ, 1985; GUIMARÃES; BORUCHOVITCH, 2004; MARINS; MOURÃO, 2007 apud GORDIANO et al., 2013). O tema é considerado importante, uma vez que o estudante necessita de motivação para se apropriar das experiências oportunizadas pelo ensino superior.
A motivação está presente em diferentes áreas da vida: no meio educacional, no social, na prática de esporte, no ambiente de trabalho, dentre outros. Assim, tratando especificamente do meio educacional, os estudantes do ensino superior enfrentam, com frequência, desafios que afetam o seu nível de motivação. Estes desafios estão associados a alguns fatores, como dúvidas com relação ao curso em que estão seguindo e o que pretendem fazer futuramente em sua profissão (GIL et al., 2012).

De acordo com Piletti (1997), a motivação é essencial para a aprendizagem, sendo, portanto, um fator fundamental. A ausência da motivação pode gerar uma queda na qualidade da aprendizagem. Desta forma, entende-se que quando apresenta um quadro de motivação adequado, o estudante tem melhores possibilidades de crescimento e pode alcançar mais sucesso na profissão.

De acordo com Todorov e Moreira (2005 apud Gil et al. 2012, p. 59):

A motivação tem sido entendida pelos teóricos como um fator psicológico, ou um conjunto de fatores e, ainda, como um processo. É responsável por uma escolha, pelo início de um comportamento que está direcionado a um objetivo e, além disso, assegura a persistência, apesar dos obstáculos.

Segundo Gil et al. (2012), renunciar a algo que no começo era desejável e agora parece muito sofrido ou difícil, talvez estabeleça a diferença entre o desejo de saber e a decisão de aprender. Aprender exige tempo e esforço, os quais dependem da motivação. Por sua vez, a desmotivação pode levar a sentimentos de angústia, fracasso, frustração, entre outros.

Conforme foi dito, motivação é como 
um impulso, um sentimento que faz com que as pessoas ajam para alcançar seus objetivos, é o que faz com que os indivíduos deem o melhor de si, façam o possível para conquistar o que desejam. Estudantes, profissionais ou pessoas que praticam esportes apresentam alguma motivação e, em sua ação, têm momentos com mais ou menos energia.

Assim, pode-se perguntar, qual seria o motivo que levaria a um comportamento mais ou menos motivado? É preciso observar nas atitudes e nas metas que dão motivo a esta ação. Tem-se como exemplo um estudante que realizará suas tarefas: ele pode estar fazendo por ser desprovido de curiosidade, ou pelo interesse de ser apenas aprovado, ou por estar motivado para adquirir novos conhecimentos para lhe trazer vantagens, também porque seus novos conhecimentos poderiam lhe dar notas boas.

Uma série de questões está relacionada à motivação dos estudantes acadêmicos, que pode ser provocada tanto por fatores internos como externos. "Uma definição geral do termo permite considerar como motivação o impulso suscitado por algum fator, podendo este impulso ser provocado por fatores externos ou internos" (ALMEIDA, 2012, p. 32).

Sendo assim, de acordo com a teoria da autodeterminação, a motivação pode ser distinguida em duas formas: intrínseca e extrínseca. Intrínseco é tudo que vem do próprio sujeito. "A motivação intrínseca abrange um comportamento mais autônomo, de causalidade interna" (GORDIANO et al., 2013, p. 5). É aquela que se origina da própria pessoa, como sua dedicação, sua competência e seu comprometimento para realizar alguma tarefa. Então a motivação intrínseca é aquela que não precisa de nenhum fator externo para obtê-la.
Em contraponto, o extrínseco é tudo que vem do meio. "A motivação extrínseca é regida por influência do ambiente social, ou por causa de contingências recompensadoras" (GORDIANO et al., 2013, p. 5). É aquela resultante de fatores externos, como os recursos de trabalho que o indivíduo recebe, o salário e o ambiente onde ele desenvolve suas tarefas.

As pessoas tendem a acreditar que as motivações intrínsecas são sempre positivas, enquanto as extrínsecas são sempre negativas, entretanto isso nem sempre é uma realidade. $\mathrm{O}$ fato é que elas atuam em conjunto e a resultante vai definir o comportamento do indivíduo no ambiente. Assim, os fatores motivacionais e afetivos têm relação direta com a aprendizagem dos alunos, de modo que o nível de desempenho e a motivação dos estudantes acadêmicos são avaliados de acordo com vários aspectos e atribuições internas e externas dos alunos.

De acordo com Sobral (2003), a teoria da autodeterminação aborda ainda um terceiro fator: a desmotivação. Esta, refere-se à ausência de qualquer motivação, intrínseca ou extrínseca. Desta forma, a teoria se completa com o grupo dos três tipos de motivação: intrínseca, extrínseca e desmotivação.

Muitos estudos sobre motivação já foram feitos, e autores identificam que a motivação e a afetividade em sala de aula são muito importantes. As interações entre professor e aluno, o que é valorizado em sala de aula, o clima psicológico, as estruturas de competição ou cooperação, entre muitas outras variáveis, podem estar relacionadas com o padrão motivacional do estudante (ALMEIDA, 2012). Quando o aluno se sente bem e à vontade na sua instituição de ensino, isso o faz querer estar presente nas atividades extras que ocorrem 
na universidade e também faz com que suas faltas nas aulas diminuam, fazendo com que ele aprenda cada vez mais durante a permanência no ambiente educacional.

Segundo Gil et al. (2012, p. 59):

Em sala de aula, a motivação implica em efeitos imediatos, como o envolvimento ativo nas tarefas do processo de aprendizagem. Sem ela, esse processo está, no mínimo, comprometido, já que representa uma queda no investimento pessoal, na qualidade e no desempenho das tarefas da aprendizagem.

A universidade em que o aluno está estudando também é um fator bastante considerável para que ele adquira motivação e conclua o curso nela iniciado. Segundo Gordiano et al. (2013), ao relacionar a qualidade do serviço educacional e a motivação acadêmica, intenciona-se apresentar resultados que indiquem que a qualidade do serviço educacional pode colaborar positivamente no resultado da aprendizagem dos alunos.

\section{METODOLOGIA}

O presente estudo é exploratório-descritivo com abordagem quantitativa. Foi utilizado como instrumento de pesquisa um questionário estruturado dividido em duas partes. A primeira parte apresenta a Escala de Motivação Acadêmica (EMA), oriunda da Academic Motivation Scale (AMS). Traduzida e validada no Brasil por Sobral (2003), a EMA é constituída de 28 itens. A segunda parte aborda as questões de natureza socioeconômica, que serviram para caracterização dos respondentes, tais como gênero, idade, estado civil e exercício de atividade remunerada. As questões foram aplicadas através de uma escala tipo Likert, de 10 pontos, onde 0 corresponde a "nada importante" e 10 corresponde a "muito importante".

A amostra é composta por 105 estudantes de dois cursos, Administração e Direito, de um Centro Universitário localizado na cidade de Fortaleza/CE. A aplicação dos questionários foi realizada no mês de abril de 2014, nos períodos da manhã e noite, nos semestres iniciais e finais de cada curso, por três pesquisadores, que deram instruções sobre como respondê-los. Não foi registrada nenhuma dificuldade por parte dos pesquisados quanto ao preenchimento do questionário.

Os dados foram trabalhados com auxílio do software SPSS (Statistical Package for the Social Sciences), versão 19.0, módulos de estatística descritiva, Análise de Médias e Análise de Variância (ANOVA).

\section{ANÁLISE DOS RESULTADOS}

A partir dos resultados da pesquisa, identifica-se que aproximadamente $43 \%$ dos alunos pesquisados são do sexo masculino e $54 \%$ do sexo feminino. Em relação à idade, 58\% dos alunos têm entre 18 e 22 anos, sendo a maioria solteira e sem filhos. Em relação à escolha do curso como primeira opção, aproximadamente $60 \%$ dos alunos afirmaram que o curso em que estão foi, sim, a primeira escolha.

Em relação a identificar qual o tipo de motivação que os alunos de cada curso apresentam, pode-se verificar os resultados no Gráfico 1. A motivação extrínseca, como é percebida, tem seus valores iguais para os dois cursos, sendo o tipo de motivação mais encontrada nos alunos, assentindo que 
as motivações externas têm um peso maior no dia a dia dos universitários. Apesar de mais complexo, foi percebido que mesmo que o índice do fator extrínseco seja maior, quando o universitário perde a motivação intrínseca, se torna mais vulnerável a se tornar desmotivado.

Ao realizar uma comparação direta entre o curso de Direito com o curso de Administração, tem-se que: $44 \%$ dos alunos do Direito estão motivados intrinsecamente e $8 \%$ estão desmotivados, enquanto na Administração se observa $43 \%$ da motivação intrínseca e 9\% de desmotivação. Os dois cursos apresentaram 48\% na motivação extrínseca (Gráfico 1).
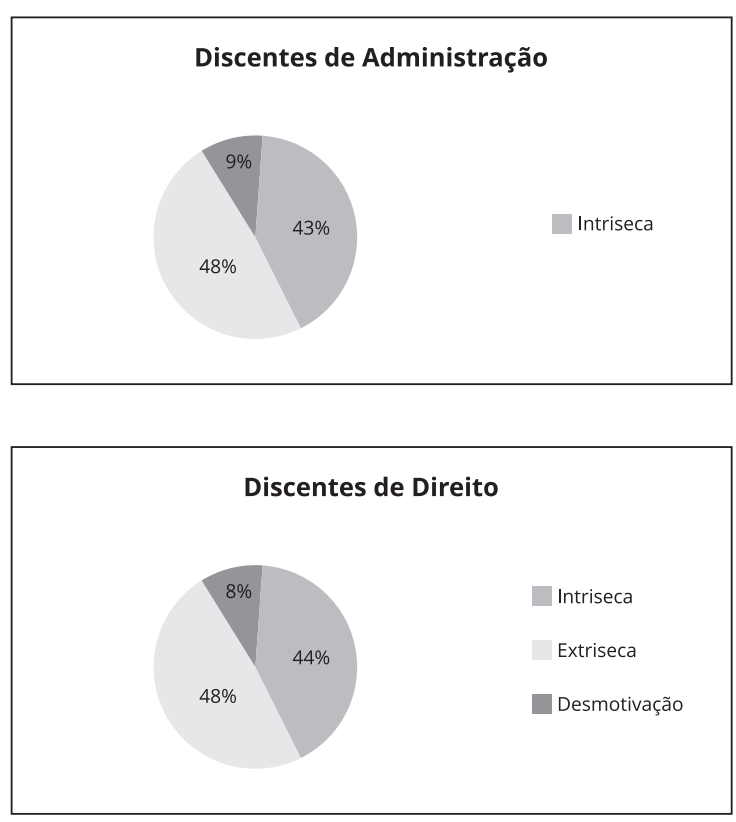

Gráfico 1 - Motivação Intrínseca, Extrínseca e Desmotivação

Fonte: dados da pesquisa (2014)

Em relação à comparação por turno, apresenta-se na Tabela 1 o resultado do curso de Administração. Foi percebido que os discentes de Administração do turno da manhã têm sua motivação extrínseca mais alta do que os alunos da noite, com a diferença aproximada de 1,7. Em relação à motivação intrínseca, se demonstrou uma diferença mais elevada, de aproximadamente 2,38. Este resultado constata que os universitários da manhã estão mais motivados que os universitários da noite. Em relação à desmotivação, os alunos de Administração de ambos os turnos apresentaram médias bem baixas, sendo aproximadamente 1,38 para o turno da manhã e 1,55 para o turno da noite.

Para saber se existe diferença significativa entre essas médias, foi realizado o teste de diferença entre médias de grupos - ANOVA. A motivação intrínseca e a motivação extrínseca apresentaram, respectivamente, os seguintes resultados: $\mathrm{F}=21,35$ e $\alpha=0,000 ; \mathrm{F}=8,418$ e $\alpha=0,007$ (Tabela 1). Esses dados demonstram que a diferença entre essas médias são significativas, corroborando o que já foi explanado. Em relação à desmotivação, os valores $\mathrm{F}=0,62$ e $\alpha=0,805$ confirmam que não existe diferença significativa em relação aos turnos pesquisados.

Tabela 1 - Curso de Administração por turno

\begin{tabular}{|l|r|r|r|r|}
\hline & \multicolumn{2}{|c|}{ Médias } & \multicolumn{2}{c|}{ ANOVA } \\
\hline & Manhã & Noite & \multicolumn{1}{c|}{ F } & Sig. \\
\hline Motivação & & & & \\
\hline Intrínseca & 7.8958 & 5.5167 & 21.354 & .000 \\
\hline Extrínseca & 8.3114 & 6.6136 & 8.418 & .007 \\
\hline Desmotivação & 1.3750 & 1.5455 & .062 & .805 \\
\hline
\end{tabular}

Fonte: dados da pesquisa (2014)

No curso de Direito, a diferença de média encontrada nas motivações intrínseca e extrínseca foi muito pequena, apresentando um nível de motivação análogo. Ao analisar os valores do teste ANOVA: $\mathrm{F}=$ 
0,600 e $\alpha=0,442 ; \mathrm{F}=1,607$ e $\alpha=0,209$, respectivamente para intrínseca e extrínseca, pode-se confirmar que não existe diferença significativa das médias dos dois turnos, como é possível observar na Tabela 2.

Um bom resultado encontrado refere-se à desmotivação no turno da noite com média aproximada de 0,8. Embora o valor encontrado referente ao turno da manhã também tenha sido baixo $(1,7576)$, com os dados do teste ANOVA pode-se inferir que existe diferença significativa entre os turnos. Desta forma, os alunos do turno da noite são os que menos estão desmotivados (TABELA 2).

Tabela 2 - Curso de Direito por turno

\begin{tabular}{|l|r|r|r|r|}
\hline & \multicolumn{2}{|c|}{ Médias } & \multicolumn{2}{c|}{ ANOVA } \\
\hline & Manhã & Noite & \multicolumn{1}{c|}{ F } & \multicolumn{1}{c|}{ Sig. } \\
\hline Motivação & & & & \\
\hline Intrínseca & 6.5417 & 6.8922 & .600 & .442 \\
\hline Extrínseca & 7.6875 & 7.2548 & 1.607 & .209 \\
\hline Desmotivação & 1.7576 & .8041 & 4.513 & .037 \\
\hline
\end{tabular}

Fonte: dados da pesquisa (2014)

Continuando a investigação entre os cursos, procedeu-se ainda a comparação das médias por semestres, dividindo-os em dois grupos: semestres iniciais (primeiro ao quarto) e semestres finais (quinto ao oitavo). Conforme os dados apresentados na Tabela 3, os resultados das motivações intrínsecas e extrínsecas foram opostos ao comparar os dois cursos. No curso de Administração, os alunos dos semestres iniciais possuem maior média na motivação extrínseca e os dos semestres finais possuem maior média na motivação intrínseca. Já no curso de Direito, os alunos que estão mais perto de se formar possuem maior média na motivação extrínseca, enquanto que os dos semestres iniciais possuem maior média na motiva- ção intrínseca.

Acredita-se que este resultado divergente pode estar relacionado com o perfil profissional de cada curso, pois demonstra que mais perto da formatura a motivação do aluno do Direito tende a estar mais relacionada a questões profissionais e de recebimento do diploma. Em contraponto, o aluno da Administração dos semestres finais está mais motivado por questões de realizações pessoais.

Em relação à desmotivação, os dois cursos apresentaram maior média nos semestres inicias, de acordo com os dados da Tabela 3. Desta forma, fica evidente que os alunos dos semestres finais, por estarem mais perto de concluir o curso e se formarem, estão mais motivados a terminá-lo.

\begin{tabular}{l} 
Tabela 3 - Médias de Motivação por \\
semestre \\
\hline \\
\hline
\end{tabular}

Fonte: dados da pesquisa (2014)

Em relação ao grau de motivação global para prosseguir com os estudos, pode-se observar na Tabela 4 que as médias encontradas nos dois cursos foram bem elevadas. Ressalta-se que nesta questão os alunos informavam livremente o quanto estavam motivados, dando valor de $0 \%$ a 100\%. No curso de Administração, percebe-se que os alunos do turno da manhã se consideram mais motivados. Esta diferença entre os turnos é significativa, comprovada pelo teste ANOVA com $F=12,112$ e $\alpha$ 
$=0,002$. Em relação ao curso de Direito, a motivação dos alunos se mostrou quase igualitária entre os dois turnos, sendo percebida um pouco mais no turno da noite.

Tabela 4 - Grau de motivação global para prosseguir nos estudos e se formar

\begin{tabular}{|l|r|r|c|c|}
\hline & \multicolumn{2}{|c|}{ Turno } & \multicolumn{2}{c|}{ ANOVA } \\
\hline & Manhã & Noite & F & Sig. \\
\hline $\begin{array}{l}\text { Motivação global } \\
\text { Administração }\end{array}$ & 92.65 & 74.78 & 12.112 & .002 \\
\hline $\begin{array}{l}\text { Motivação global } \\
\text { Direito }\end{array}$ & 82.67 & 89.77 & 3.456 & .068 \\
\hline
\end{tabular}

Fonte: dados da pesquisa (2014)

\section{CONSIDERAÇÕES FINAIS}

A partir dos dados obtidos, pode-se atingir o objetivo proposto neste estudo que era identificar a motivação para aprendizagem dos discentes de Administração e Direito de um Centro Universitário em Fortaleza-Ce e as possíveis diferenças em razão dos cursos e turnos dos alunos. Foi possível comparar os dois cursos em questão e seus turnos (manhã e noite), e identificar a motivação extrínseca e intrínseca, e desmotivação de cada um. Percebeu-se que neste estudo as motivações dos discentes são bastante elevadas e equivalentes, tanto entre si, como comparadas às duas graduações.

Pode-se então considerar que a motivação dos universitários pode ser intrínseca e extrínseca, e que apesar do tamanho desta amostra, percebeu-se que a motivação pode ser diferente dentro da mesma instituição, variando de acordo com o turno. Nesta pesquisa viu-se que na Administração os alunos do turno da manhã são mais motivados do que os da noite. No curso de Direto, a pequena diferença não é representativa, o que se infere que os alunos dos dois turnos possuem o mesmo nível de motivação.

Em relação à desmotivação, os resultados se invertem. Os alunos de Administração dos dois turnos não apresentaram diferença significativa entre as médias. Já os alunos de Direito do turno da noite apresentaram uma menor desmotivação que os da manhã. Cabe ressaltar que todas as médias de desmotivação foram muito baixas, sendo a maior delas 1,75. Este dado é importante, pois se pode aferir que, de uma forma geral, a amostra pesquisada encontra-se bastante motivada em seu curso.

$O$ resultado deste estudo não pode ser generalizado, mas é de grande importância para a instituição, funcionando como um feedback. Os dados podem ser utilizados para análise e viabilização de uma solução plausível para obter um índice de motivação ainda maior. Ao analisar o comportamento do aluno em relação a sua motivação, pode apresentar um bom instrumento para a gestão da universidade. Contribui, ainda, com a área acadêmica, ao utilizar a escala EMA e fomentar as discussões acerca de motivação estudantil.

Sugere-se a continuidade deste estudo, com a ampliação do universo da amostra para abranger todos os cursos dentro da mesma instituição e ainda a repetição da pesquisa em momentos posteriores com os mesmos cursos, intencionando identificar se existe variação na motivação dos estudantes. Estas pesquisas podem ser feitas de forma sistemática, tornando-se uma forma validada de se avaliar a instituição e envolver os gestores e os professores na busca da constante motivação dos alunos. Sugere-se ainda a aplicação deste estudo em diferentes instituições privadas e públicas.

Por fim, sugere-se um aprofundamento deste estudo, analisando em conjun- 
to com a motivação do aluno, constructos de percepção da qualidade. Desta forma, o confronto de pesquisas no mesmo tema e relacionados à qualidade do ensino propicia a formação de conhecimentos empíricos para auxiliar a gestão empresarial das instituições, além de identificar similaridades e diferenças no setor educacional.

\section{MOTIVATION IN UNIVERSITY COURSES: A STUDY WITH THE STUDENTS OF THE COURSES OF MANAGEMENT AND LAW}

\section{SUMMARY}

Thestudent'smotivationisoneoftheessential components for learning. According to the theory of self-determination, that motivation can be intrinsic and extrinsic and its absence generates demotivation. The aim of this paper work is to identify the motivation for learning of the students of Administration and Law of a University Center in Fortaleza-Ce and the possible differences in terms of the courses, the students' day periods and semesters. In order to reach a reasonable result, a quantitative research was carried out using as research instrument a questionnaire adapted and validated for higher education by Sobral (2003). The scale which was employed uses the constructs of extrinsic and intrinsic motivation and the attitudes of demotivation. The sample resulted in 105 valid questionnaires. The analysis of the data showed that the students of both courses are motivated by intrinsic and extrinsic factors, and that there are differences among the turns or day periods of study in the Course of Administration.
Keywords: Motivation. Higher Education. Administration. Law.

\section{REFERÊNCIAS}

ALMEIDA, D. M. S. A motivação do aluno no ensino superior: um estudo exploratório. 2012. 149f. Dissertação (Mestrado Educação) - Universidade Estadual de Londrina, Paraná, 2012. Disponível m: $<$ http:// www.uel.br/pos/mestredu/images/stories/ downloads/dissertacoes/

2012/2012_-_ALMEIDA_Debora_Menegazzo_Sousa.pdf $>$. Acesso em: 05 abr. 2014.

GIL, E. S. et al. Estratégias de ensino e motivação de estudantes no ensino superior. Vita et Sanitas, Trindade-Go, n. 6, p. 57-81, jan./dez. de 2012. Disponível em:< http://fug.edu.br/revista_6/pdf/artigo4. pdf $>$. Acesso em: 10 abr. 2014.

GORDIANO, E. C. S. et al. A percepção do cliente: qualidade na educação superior e motivação discente. In : Seminário em administração - SemeAd , 16., 2013, São Paulo. Anais... São Paulo: FEA- USP, 2013. Disponível em: <http://semead6.tempsite. ws/16semead/resultado/trabalhospdf/882. pdf $>$. Acesso em: 05 abr. 2014.

GUIMARÃES，S.É.R.; BORUCHOVITCH, E. O Estilo Motivacional do Professor e a Motivação Intrínseca dos estudantes: uma Perspectiva da Teoria da Autodeterminação. Psicologia Reflexão e Crítica, Rio Grande do Sul, v.17, n.2, p.143-150, 2004. 
JOLY, M. C. R. A.; PRATES, E. A. R. Avaliação da Escala de Motivação Acadêmica em estudantes paulistas: propriedades psicométricas, Psico-USF, Itatiba, v. 16, n. 2, p. 175-184, 2011.

MATHIAS, J. F. C. M. Breves Considerações sobre a Evolução do Ensino Superior do Brasil no Período Recente, Revista CADE-FMJ, v.10, p.169-180, 2004.

PILETTI, N. Psicologia educacional. São Paulo: Ática, 1997.

SILVA FILHO, R.L.L.; MOTEJUNAS P. R.; HIPÓlitO O.; LOBO, M.B.C.M. A Evasão No Ensino Superior Brasileiro. Cadernos de pesquisa, São Paulo, v.37, n.132, p. 641-659, set./dez. 2007.

SOBRAL, D. T. Motivação do aprendiz de Medicina: uso da escala de motivação acadêmica, Psicologiateoria e Pesquisa, Brasília, v.19, n.1, p. 25-31, jan./abr. 2003. 